\title{
Associations between cardiorespiratory fitness and weight loss in patients with severe obesity undergoing an intensive lifestyle intervention program: retrospective cohort study
}

\author{
Jarle Berge ${ }^{1,2,3^{*}}$ (D), Øyvind Støren ${ }^{3}$, Jens K. Hertel ${ }^{1}$, Espen Gjevestad ${ }^{1,2,4}$, Milada Cvancarova Småstuen ${ }^{1}$ and \\ Jøran Hjelmesæth ${ }^{1,5}$
}

\begin{abstract}
Background: To assess the association between cardiorespiratory fitness (CRF) and weight changes in treatment seeking patients with severe obesity who underwent a 1-year intensive lifestyle intervention (ILI) program.

Methods: Retrospective cohort study conducted at a tertiary care outpatient rehabilitation center from November 1, 2013 through January 1, 2017. CRF was measured as maximal oxygen consumption during a maximal oxygen uptake $\left(\mathrm{VO}_{2 \max }\right)$ test on a treadmill or bicycle at baseline and after 3 months.

Results: A total of 180 patients had a baseline mean (SD) BMl 41.1 (4.8) kg/m² and CRF of 79.4 (14.9) $\mathrm{mL} \cdot \mathrm{kg}^{-0.75} \cdot \mathrm{min}^{-1}$. Patients with a baseline CRF above median achieved a greater 3-month and 1-year weight loss compared with patients with CRF below median; mean $(95 \% \mathrm{Cl}) 2.5 \mathrm{~kg}(1.3,3.8)$ and $4.0 \mathrm{~kg}(0.8,7.2)$, respectively. In addition, patients with 3 -month changes of CRF above median had $4.0 \mathrm{~kg}(0.9,7.1)$ greater weight loss at 1-year follow-up than those below median.
\end{abstract}

Conclusions: Among patients with severe obesity who underwent a 1-year ILI program, higher baseline CRF was associated with significantly larger weight loss after 3 months and 1 year. In addition, those with higher initial 3-month CRF changes had greater weight loss at 1 year.

Trial registration: Retrospectively registered in Regional Committees for Medical and Health Research Ethics (REC) south east September 22, 2016 (2016/1414) and clinicaltials.gov August 13, 2018 (identifier: NCT03593798).

Keywords: $\mathrm{VO}_{2 \max }$, Weight change, Severe obesity, Lifestyle intervention

\section{Background}

Low cardiorespiratory fitness (CRF) is associated with lower energy expenditure [1, 2], higher body mass index (BMI) $[3,4]$ and increased waist circumference [5]. Patients with severe obesity therefore often have reduced CRF [3, 4, 6, 7]. Since lower CRF can result

\footnotetext{
* Correspondence: Jarle.berge@siv.no

'Morbid Obesity Centre, Vestfold Hospital Trust, Box 2168, 3103 Tønsberg,

Norway

${ }^{2}$ Clinic Medicine and Rehabilitation, Vestfold Hospital Trust, Tønsberg,

Norway

Full list of author information is available at the end of the article
}

both in a lower daily activity level [8] and a lower potential for energy expenditure during activities [9], improving CRF could potentially induce weight reduction [10]. In line with this, improvements in CRF have been associated with decreased amounts of subcutaneous fat, visceral fat, liver fat and total fat mass, as well as decreased waist and hip circumference [11-14]. Importantly, exercise and increased CRF seem to both promote greater fat mass loss and assist preservation of lean mass, compared with energy restriction alone during weight loss interventions [15]. Further, a large prospective cohort study showed that

(c) The Author(s). 2019 Open Access This article is distributed under the terms of the Creative Commons Attribution 4.0 International License (http://creativecommons.org/licenses/by/4.0/), which permits unrestricted use, distribution, and 
improvements in CRF were associated with attenuated age-related weight gain in healthy middle-age adults [16].

The most used measure of CRF is maximal oxygen consumption $\left(\mathrm{VO}_{2 \max }\right)$. Each liter of oxygen consumed liberates approximately $5 \mathrm{kcal}$, dependent upon the intensity of work [9]. This means that at any given relative work intensity, a higher $\mathrm{VO}_{2 \max }$ is accompanied with a higher energy expenditure. Energy expenditure has been shown to correlate with the rate of body weight change [17], and, accordingly, CRF may affect body weight change. However, to our knowledge, no previous study has addressed the association between CRF and body weight change in patients with severe obesity undergoing an intensive lifestyle intervention (ILI) program. Thus, the potentially predictive effect of CRF on weight loss is uncertain.

The primary aim of the present study was to investigate the association between CRF and weight loss in treatment seeking patients with severe obesity, who participated in a 1-year ILI program at a tertiary care center. We hypothesized that CRF above median at baseline would be associated with greater weight loss at the 3-month and 1-year follow-up, since a higher capacity for oxygen consumption will imply a higher capacity for energy expenditure, and that increasing CRF the first 3 months would be associated with greater level of weight loss at the 1-year follow-up.

\section{Methods}

\section{Study design}

This is a retrospective analysis of data from a cohort of patients with severe obesity who underwent a 1year ILI program at a tertiary care outpatient rehabilitation center in Norway between November 1, 2013 and January 1, 2017.

\section{Participants}

A total of 195 consecutive patients with severe obesity (BMI $\geq 40 \mathrm{~kg} / \mathrm{m}^{2}$, or $35-39.9 \mathrm{~kg} / \mathrm{m}^{2}$ with at least one obesity related co-morbidity) seeking treatment between 2013 and 2015 at the Clinic of Physical Medicine and Rehabilitation, Vestfold Hospital Trust, were eligible for this study. These patients were informed through an opt-out consent letter which stated that previously collected information during the ILI program would be used to answer the research questions stated in this project. Patients had a minimum of three weeks to opt-out of the study, and only two patients reserved usage of their personal information in this study.

Patient data from baseline to approximately 3month and 1-year follow-up were included in the analyses. The study was approved by the Regional
Committees for Medical and Health Research Ethics (REC) South East (2016/1414) and registered at clinicaltials.gov (identifier: NCT03593798).

\section{Interventions}

The ILI program has been described in detail previously (Additional file 1) [18]. In brief, the program included both calorie restriction and physical exercise, and it aimed to help patients change their lifestyle, improve their CRF, and to achieve at least 5-10\% weight loss. The patients received a dietary plan with an energy restriction of approximately $1000 \mathrm{kcal}$ per day and were informed to follow restriction throughout the year. They had regular exercise sessions to increased energy expenditure during 3-month and were informed to continue regular exercise sessions throughout the year. The 3-month ILI program consisted of group- and individual treatments 3 days a week, including two supervised exercise sessions (duration 60-90 min.) per day and two lectures on healthy lifestyle behavior per day (Time schedule- Additional file 1). Exercise sessions included one weight-bearing activity and one water- based exercise per day. The exercise sessions were mainly of moderate to high aerobic intensity (4-8 metabolic equivalents), but also included some resistance sessions $(75-90 \%$ of one repetition maximum) [19]. From month 3 to 12 , patients attended monthly sessions including group exercise, group lectures and individual sessions with an interdisciplinary team that included a nurse, a medical doctor and physical educators.

\section{Outcome and predictor variables}

The primary outcomes were changes in body weight between baseline and the 3-month and 1-year followup. Changes in waist circumference were also assessed. Baseline CRF and 3-month change in CRF were treated as exposure variables and possible predictors of weight loss.

\section{Measurements}

CRF measured as $\mathrm{VO}_{2 \max }$ [20] was assessed at baseline and after 3 months. $\mathrm{VO}_{2 \max }$ is expressed as the absolute volume of oxygen consumed in liters $(\mathrm{L} / \mathrm{min})$ or related to body weight $\left(\mathrm{mL} \cdot \mathrm{kg}^{-1} \cdot \mathrm{min}^{-1}\right) \quad[20] . \quad \mathrm{VO}_{2 \max }$ expressed relative to body weight $\left(\mathrm{mL} \cdot \mathrm{kg}^{-1} \cdot \mathrm{min}^{-1}\right)$ has been shown to underestimate CRF in heavy subjects, and overestimate CRF in light subjects. $\mathrm{VO}_{2 \max }$ scaled relative to the body weight raised to the power of 0.75 $\left(\mathrm{mL} \cdot \mathrm{kg}^{-0.75} \cdot \mathrm{min}^{-1}\right)$ has eliminated the differences [2124]. In order to account for $\mathrm{VO}_{2 \max }$ related to body size and weight, the results of $\mathrm{VO}_{2 \max }$ were allometrically scaled to $\mathrm{mL} \cdot \mathrm{kg}^{-0.75} \cdot \mathrm{min}^{-1}$. 
The $\mathrm{VO}_{2 \max }$ test was mainly performed as an incremental treadmill test on Woodway ELG 55 (Waukesha, Germany) or, for patients with walking restrictions $(n=8)$, as an incremental bicycle test (Lode Corival V3, Lode BV, Groningen, Netherlands). For the treadmill test, velocity $\left(0.5 \mathrm{~km} \cdot \mathrm{h}^{-1}\right)$ or inclination (1\%) were increased every $30 \mathrm{~s}$, until voluntary exhaustion. During the bicycle test brake power was increased by $25 \mathrm{~W}$ every $30 \mathrm{~s}$ until voluntary exhaustion. The duration of the test ranged between 4 and $10 \mathrm{~min}$. Voluntary exhaustion, respiratory exchange ratio $\geq 1.05$, calculated heart rate $\geq 95 \%$ of maximal heart rate, Borg scale $\geq 17$ or flattening of $\mathrm{VO}_{2}$ curve were used to evaluate if $\mathrm{VO}_{2 \max }$ had been achieved. $\mathrm{VO}_{2 \max }$ was set as the highest sum of three consecutive $10 \mathrm{~s}$ measurements. Maximal heart rate was set as the highest observed value. Oxygen uptake was registered using the Jaeger oxycon pro ergospirometry test system (Jaeger Oxycon Pro JLAB 5.x, Hoechberg, Germany). The system includes a mixing chamber with oxygen $\left(\mathrm{O}_{2}\right)$ and carbon dioxide $\left(\mathrm{CO}_{2}\right)$ analyzed continuously every $10 \mathrm{~s}$. Before each test, the device was checked and calibrated with room air and a certified gas containing $16 \% \mathrm{O}_{2}$ and $4 \% \mathrm{CO}_{2}$. Volume calibration was performed before each test, with an automatic syringe (2-L/s high flow and $0.2 \mathrm{~L} / \mathrm{s}$ low flow) in Jaeger oxycon pro ergospirometry test system. A face mask (Hans Rudolph V2 mask) with different size (petit, XS, S, M) was used to collect expired air during the test. HR was collected continuously through the tests with Polar WearLink+ H7 bluetooth and Polar RCX 5 (Polar RCX 5, Polar Electro OY, Finland). The patients were instructed to refrain from eating $2 \mathrm{~h}$ and smoking $4 \mathrm{~h}$ before measurements, as well as to only drink water and to refrain from high intensity exercise in the last $24 \mathrm{~h}$ prior to measuring.

Body weight was measured with patients wearing light clothing and no shoes on Scanvaegt DS-530 (Århus, Denmark). Height was measured using a Seca (B.D.G.M) wall-mounted measuring tape. BMI was calculated as weight in kilograms divided by height in meters squared. Waist circumference was measured midway between the bottom edge of the lower rib and upper iliac crest in the horizontal plane. All anthropometric measures were performed at baseline, and after 3 months and 1 year.

\section{Sample size}

No formal sample-size calculations were performed. All patients who attended the outpatient rehabilitation center during the study period of November 1, 2013 to January 1, 2017, in addition to those who completed follow-up at baseline and 3-month, baseline and 1-year, or at baseline, 3-month and 1-year follow-up, were asked to participate.

\section{Statistical analyses}

All statistical analyses were performed using the Statistical Package for Social Sciences (SPSS) version 23 (Chicago, IL). Baseline CRF values were tested for normal distribution by visual inspection of QQ-plot, and were found to be normally distributed. Descriptive statistics are presented as mean and standard deviation (SD) unless otherwise specified. Independent samples t-tests or Fisher's exact test as appropriate were used to analyze differences in outcomes between groups. Analysis of covariance (ANCOVA) adjusted for age, gender and baseline value were performed in order to identify potential differences between groups from baseline to 3-month and 1-year follow-up. Pearson bivariate correlation tests were used in order to investigate the correlations between initial CRF and weight reduction, and between improvement in CRF and weight reduction. In order to evaluate the strength of the correlations, Cohen's $\mathrm{f}^{2}$ tests were performed. All P- values $<0.05$ were considered statistically significant and all tests were two-sided.

\section{Results}

Of 195 patients eligible for this study, two patients declined participation, and 13 patients did not complete measurements at baseline (Fig. 1). The remaining 180 patients underwent baseline measurements, six of whom did not complete the first 3 months (median 11 weeks, range 9-16) of the ILI program, leaving 174 patients to be included in the analysis of the 3-month anthropometric data. Further, 14 patients did not complete measurements at 12 months (median 11 months, range 9-14) leaving 160 patients to be included in the analysis of the 1-year anthropometric data (Fig. 1). In addition, 143 patients completed CRF measurements at baseline and the 3months follow-up, and weight measurements at the 1-year follow-up.

Overall, the 180 (79\% female) patients had a baseline mean (SD) age of 43.5 (9.4) years, BMI $41.1(4.8) \mathrm{kg} / \mathrm{m}^{2}$, body weight 118.8 (19.2) $\mathrm{kg}$ and CRF 79.4 (14.9) $\mathrm{mL} \cdot \mathrm{kg}^{-0.75} \cdot \mathrm{min}^{-1}$ (Table 1). Males had significantly higher age, body weight, waist circumference and CRF than females (Table 1).

Compared with patients who had a baseline CRF below median $\left(78.3 \mathrm{~mL} \cdot \mathrm{kg}^{-0.75} \cdot \mathrm{min}^{-1}\right)$, those with a CRF above median had a mean $(95 \% \mathrm{CI}) 2.5(1.3-3.8) \mathrm{kg}$ greater 3-month weight loss (Table 2). Further, the proportion $(95 \% \mathrm{CI})$ of patients achieving a 3-month weight loss of $\geq 10 \%$ was significantly higher in those with a baseline CRF above median compared with those 


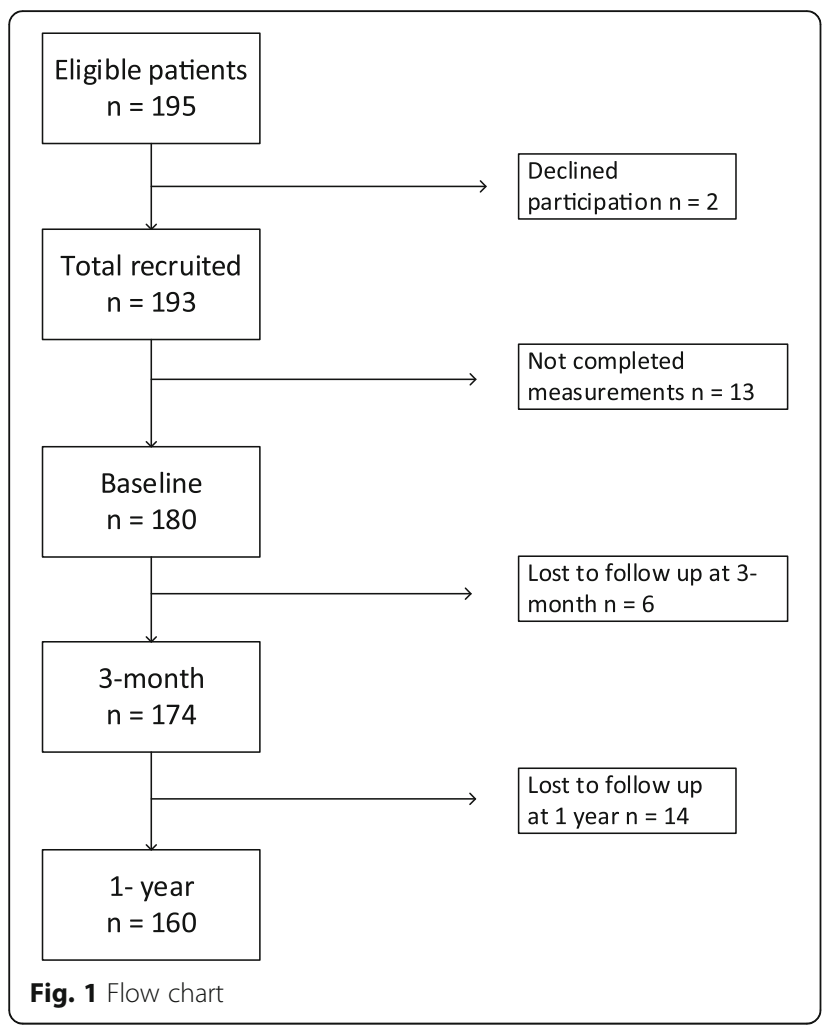

below median $28 \%(18-37)$ vs $7 \%$ [2-12] (Fig. 2). In addition, higher baseline CRF was weakly correlated with 3-month weight loss, $\mathrm{r}=-0.17, P=0.026$ (Cohen's $\mathrm{f}^{2}=0.03$ ) (Additional file 2: Figure S1).

Patients with baseline CRF values above median had a mean of $4.0(0.8,7.2) \mathrm{kg}$ greater 1-year weight loss than those with CRF values below median (Table 3 ). However, the proportion of patients achieving a 1-year weight loss of $\geq 10 \%$ was not significantly higher in those with a baseline CRF above median compared with those below median 38\% (27-48) vs 31\% (21-42) (Fig. 3). In addition, higher baseline CRF was weakly correlated with 1-year weight loss, $\mathrm{r}=-0.17, P=0.028$ $\left(\right.$ Cohen's $\mathrm{f}^{2}=0.03$ ) (Additional file 2: Figure S2).

Patients who achieved an above median 3-month increase in CRF had 4.0 (0.9-7.1) kg greater weight loss at 1-year follow-up than those below median (Table 4). Further, the proportion of patients achieving a 1-year weight loss of $\geq 10 \%$ was significantly higher in those with CRF changes above median compared with those below median $47 \%$ (35-59) vs 27\% (16-37) (Fig. 4). In addition, the 3-month change in CRF was weakly correlated with 1-year weight loss, $\mathrm{r}=-0.26, \quad P=0.002$ $\left(\right.$ Cohen's $\left.f^{2}=0.07\right)$ (Additional file 2: Figure S3).

\section{Discussion}

In accordance with our hypotheses, patients with higher (above median) CRF before treatment achieved significantly greater 3-month and 1-year average weight loss; $2.5 \mathrm{~kg}$ and $4.0 \mathrm{~kg}$, respectively, than those with lower CRF. Further, those with larger (above median) initial 3-month improvements in CRF had on average $4.0 \mathrm{~kg}$ greater 1-year weight loss than those with smaller CRF changes. In addition, the proportion of patients achieving a weight loss of $\geq 10 \%$ after 3 months was significantly higher in those with higher CRF at baseline, while the proportion of patients achieving a weight loss of $\geq 10 \%$ after 1 year was higher among the patients who achieved larger initial 3-month improvement of CRF.

To the best of our knowledge, this is the first study of patients with severe obesity undergoing an ILI program which assesses the potential predictive effects of pre-treatment CRF and initial changes in CRF on achieved weight loss. A previous cross-sectional study reported that both lower resting metabolic rate and CRF were associated with higher BMI, but the study design precluded any assessment of potential effects of CRF on weight loss [3]. The significant association between baseline CRF and weight loss at the 3-month and 1-year follow-up in the present study may be

Table 1 Baseline demographics, anthropometrics and cardiorespiratory fitness among treatment seeking patients according to gender

\begin{tabular}{|c|c|c|c|c|}
\hline Variable & Total $(n=180)$ & Males $(n=38)$ & Females $(n=142)$ & $P$-value \\
\hline Caucasian & $174(97 \%)$ & $37(97 \%)$ & $137(96 \%)$ & \\
\hline Age (years) & $43.5(9.4)$ & $47.0(10.2)$ & $42.6(9.0)$ & 0.010 \\
\hline $\mathrm{BMI}\left(\mathrm{kg} / \mathrm{m}^{2}\right)$ & $41.1(4.8)$ & $42.3(5.0)$ & $40.8(4.7)$ & 0.086 \\
\hline Weight (kg) & $118.8(19.2)$ & $137.3(20.5)$ & $113.8(15.6)$ & $<0.001$ \\
\hline Waist circumference (cm) & $116.8(12.9)$ & $130.0(12.1)$ & $113.4(10.7)$ & $<0.001$ \\
\hline $\mathrm{VO}_{2 \max }\left(\mathrm{mL} \cdot \mathrm{kg}^{-0.75} \cdot \mathrm{min}^{-1}\right)$ & $79.4(14.9)$ & $86.5(18.9)$ & $77.4(13.1)$ & 0.007 \\
\hline $\mathrm{VO}_{2 \max }\left(\mathrm{mL} \cdot \mathrm{kg}^{-1} \cdot \mathrm{min}^{-1}\right)$ & $24.2(4.7)$ & $25.4(5.8)$ & $23.9(4.3)$ & 0.072 \\
\hline $\mathrm{VO}_{2 \max }\left(\mathrm{L} \cdot \mathrm{min}^{-1}\right)$ & $2.85(0.63)$ & $3.45(0.78)$ & $2.68(0.46)$ & $<0.001$ \\
\hline
\end{tabular}

Data are presented as numbers (\%) or mean (SD), independent samples t-test 
Table 2 Anthropometrics, cardiorespiratory fitness and weight changes at the 3-mo follow-up

\begin{tabular}{|c|c|c|c|c|c|}
\hline \multicolumn{6}{|c|}{ Cardiorespiratory fitness $\left(\mathrm{mL} \cdot \mathrm{kg}^{-0.75} \cdot \mathrm{min}^{-1}\right)$} \\
\hline & $\begin{array}{l}\text { Below median } \\
(N=87)\end{array}$ & $\begin{array}{l}\text { Above median } \\
(\mathrm{N}=87)\end{array}$ & $P$-value & $\begin{array}{l}\text { Adjusted differences } \\
\text { between groups }\end{array}$ & $\begin{array}{l}\text { P-value adjusted } \\
\text { differences between groups }\end{array}$ \\
\hline \multicolumn{6}{|l|}{ Baseline } \\
\hline Age (year) & $45.8(10.1)$ & $41.2(7.9)$ & 0.001 & & \\
\hline Gender (female) & $75(86.2 \%)$ & $63(72.4 \%)$ & 0.039 & & \\
\hline Weight (kg) & $119.9(18.9)$ & $117.4(19.6)$ & 0.401 & & \\
\hline $\mathrm{BMI}\left(\mathrm{kg} / \mathrm{m}^{2}\right)$ & $42.2(4.5)$ & $40.0(5.0)$ & 0.003 & & \\
\hline Waist circumference $(\mathrm{cm})$ & $119.7(11.7)$ & $113.8(13.2)$ & 0.004 & & \\
\hline $\mathrm{VO}_{2 \max }\left(\mathrm{mL} \cdot \mathrm{kg}^{-0.75} \cdot \mathrm{min}^{-1}\right)$ & $68.0(8.9)$ & $91.1(10.0)$ & $<0.001$ & & \\
\hline $\mathrm{VO}_{2 \max }\left(\mathrm{mL} \cdot \mathrm{kg}^{-1} \cdot \mathrm{min}^{-1}\right)$ & $20.7(2.9)$ & $27.8(3.4)$ & $<0.001$ & & \\
\hline $\mathrm{VO}_{2 \max }\left(L \cdot \mathrm{min}^{-1}\right)$ & $2.46(0.44)$ & $3.24(0.53)$ & $<0.001$ & & \\
\hline \multicolumn{6}{|l|}{$3-\mathrm{mo}$} \\
\hline Weight (kg) & $112.6(18.0)$ & $108.5(18.4)$ & 0.134 & & \\
\hline BMI $\left(\mathrm{kg} / \mathrm{m}^{2}\right)$ & $39.6(4.3)$ & $37.0(4.9)$ & $<0.001$ & & \\
\hline Waist circumference $(\mathrm{cm})$ & $111.2(11.9)$ & $104.7(12.8)$ & 0.001 & & \\
\hline $\mathrm{VO}_{2 \max }\left(\mathrm{mL} \cdot \mathrm{kg}^{-0.75} \cdot \mathrm{min}^{-1}\right)^{\#}$ & $77.9(10.8)$ & $101.5(15.0)$ & $<0.001$ & & \\
\hline $\mathrm{VO}_{2 \max }\left(\mathrm{mL} \cdot \mathrm{kg}^{-1} \cdot \mathrm{min}^{-1}\right)^{\#}$ & $24.1(3.4)$ & $31.5(4.9)$ & $<0.001$ & & \\
\hline$V O_{2 \max }\left(L \cdot \min ^{-1}\right)^{\#}$ & $2.68(0.47)$ & $3.40(0.67)$ & $<0.001$ & & \\
\hline \multicolumn{6}{|l|}{ Changes 3-mo } \\
\hline Weight change (\%) & $-6.0(-6.7,-5.4)$ & $-7.6(-8.3,-6.9)$ & 0.002 & & \\
\hline Weight change (kg) & $-7.3(-8.1,-6.4)$ & $-9.0(-9.9,-8.0)$ & 0.008 & $2.5(1.3,3.8)$ & $<0.001$ \\
\hline BMI change $\left(\mathrm{kg} / \mathrm{m}^{2}\right)$ & $-2.6(-2.8,-2.3)$ & $-3.0(-3.3,-2.7)$ & 0.026 & $0.9(0.4,1.3)$ & $<0.001$ \\
\hline
\end{tabular}

Data are presented as mean (SD or $\mathrm{Cl} 95 \%$ ) or numbers (\%). Groups are divided by $\mathrm{VO}_{2 \max }$ median $\left(78.3 \mathrm{~mL} \cdot \mathrm{kg}^{-0.75} \cdot \mathrm{min}^{-1}\right)$. Differences between groups analyzed using independent samples t-test or Fisher's exact test (gender) as appropriate. Adjusted differences between groups in term of changes were analyzed using analysis of covariance (ANCOVA) including age, gender and baseline value of outcome variable as covariates. ${ }^{*}, N=74$ below median, $N=82$ above median

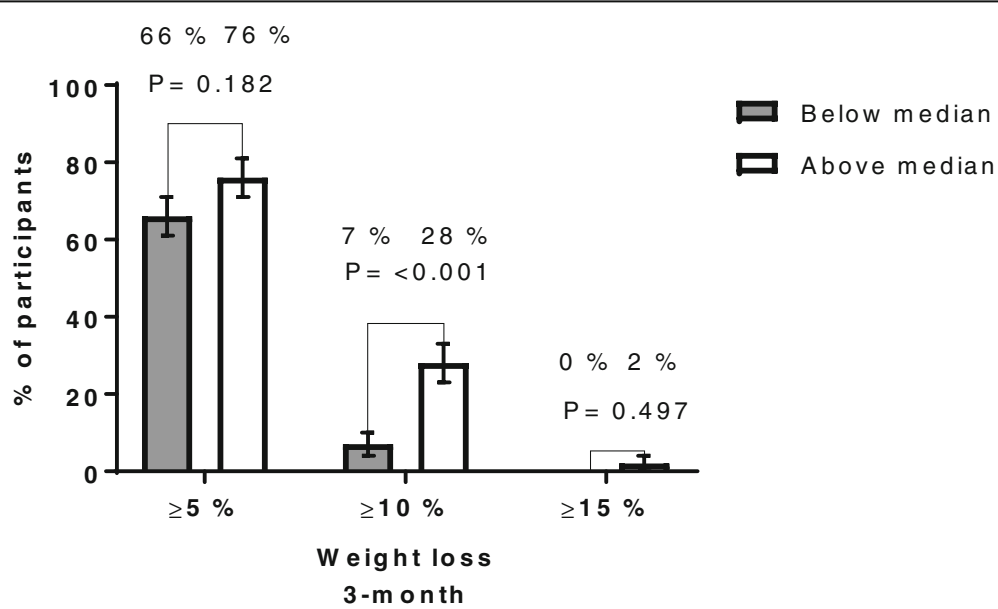

Fig. 2 Proportions of patients in the two groups who at 3-month follow-up achieved at least 5, 10\% or 15\% weight loss. Data are presented as percentage of participants with standard error of the mean (SEM), either above or below baseline CRF median, who achieved at least 5, 10\% or 15\% weight loss at 3-month follow-up. Baseline CRF above median, $N=87$. Baseline CRF below median, $N=87$. In the above median CRF group, the number of patients who achieved at least $5,10 \%$ or $15 \%$ was 66 (76\%, SEM 5\%), 24 (28\%, SEM 5\%), 2 (2\%, SEM 2\%), respectively. In the below median CRF group, the number of patients who achieved at least 5, 10\% or 15\% was 57 (66\%, SEM 5\%), 6 (7\%, SEM 3\%), 0 (0\%, SEM 0\%), respectively 


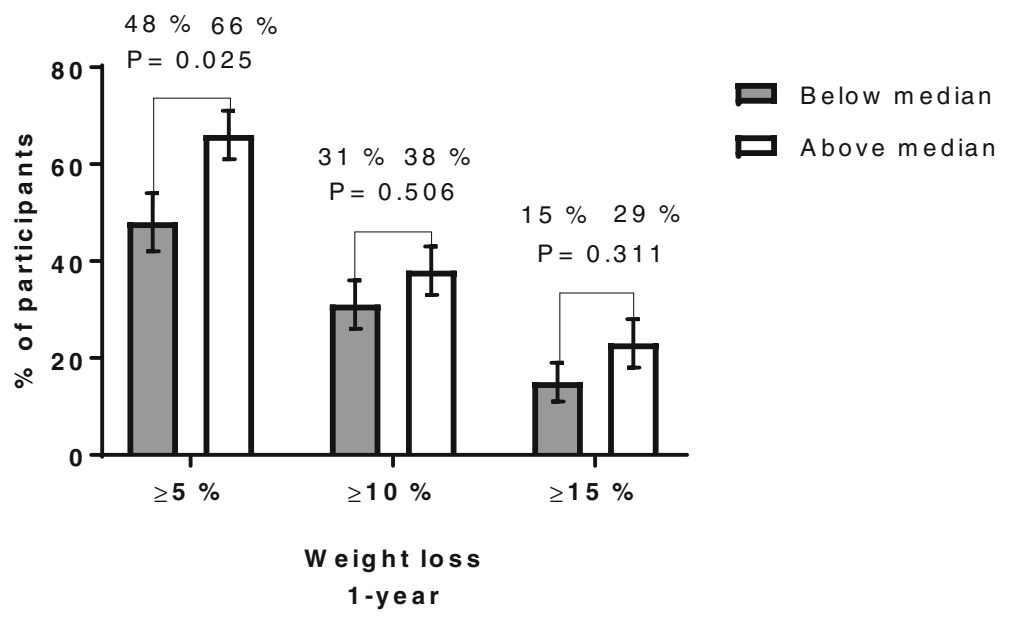

Fig. 3 Proportions of patients in the two groups who at 1-year follow-up achieved at least 5, 10\% or 15\% weight loss. Data are presented as percentage of participants with standard error of the mean (SEM), either above or below baseline CRF median, who achieved at least 5, 10\% or 15\% weight loss at 1year follow-up. Baseline CRF above median, $N=80$. Baseline CRF below median, $N=80$. In the above median CRF group, the number of patients who achieved at least 5, $10 \%$ or $15 \%$ was 53 (66\%, SEM 5\%), 30 (38\%, SEM 5\%), 18 (23\%, SEM 5\%), respectively. In the below median CRF group, the number of patients who achieved at least 5, 10\% or 15\% was 38 (48\%, SEM 6\%), 25 (31\%, SEM 5\%), 12 (15\%, SEM 4\%), respectively

explained by the potential of greater energy expenditure in patients with higher CRF [25].

The measurement of CRF as $\mathrm{VO}_{2 \max }$ [20], the gold standard for measurement of indirect calorimetry, and the number of patients undergoing a 1-year ILI program, strengthen the results. Since the ILI program also included energy restrictions, the weight loss results might also have been affected by this. We cannot exclude the possibility that the patients with the greatest improvement in CRF may also have followed

Table 3 Anthropometrics, cardiorespiratory fitness and weight changes at the 1-yr follow-up

\begin{tabular}{|c|c|c|c|c|c|}
\hline \multicolumn{6}{|c|}{ Cardiorespiratory fitness $\left(\mathrm{mL} \cdot \mathrm{kg}^{-0.75} \cdot \mathrm{min}^{-1}\right)$} \\
\hline & $\begin{array}{l}\text { Below median } \\
(n=80)\end{array}$ & $\begin{array}{l}\text { Above median } \\
(n=80)\end{array}$ & $P$-value & $\begin{array}{l}\text { Adjusted differences } \\
\text { between groups }\end{array}$ & $\begin{array}{l}P \text { - value adjusted } \\
\text { differences between groups }\end{array}$ \\
\hline \multicolumn{6}{|l|}{ Baseline } \\
\hline Gender (female) & $68(85.0 \%)$ & $55(68.7 \%)$ & 0.024 & & \\
\hline Age (years) & $45.8(10.1)$ & $41.9(7.5)$ & 0.006 & & \\
\hline Weight (kg) & $120.2(19.5)$ & $117.7(19.6)$ & 0.427 & & \\
\hline BMI $\left(\mathrm{kg} / \mathrm{m}^{2}\right)$ & $42.2(4.6)$ & $39.9(4.8)$ & 0.002 & & \\
\hline Waist circumference $(\mathrm{cm})$ & $119.8(12.2)$ & $114.7(13.8)$ & 0.015 & & \\
\hline $\mathrm{VO}_{2 \max }\left(\mathrm{mL} \cdot \mathrm{kg}^{-0.75} \cdot \mathrm{min}^{-1}\right)$ & $67.8(9.1)$ & $91.5(10.2)$ & $<0.001$ & & \\
\hline $\mathrm{VO}_{2 \max }\left(\mathrm{mL} \cdot \mathrm{kg}^{-1} \cdot \mathrm{min}^{-1}\right)$ & $20.6(2.9)$ & $27.9(3.4)$ & $<0.001$ & & \\
\hline $\mathrm{VO}_{2 \max }\left(L \cdot \mathrm{min}^{-1}\right)$ & $2.46(0.45)$ & $3.26(0.54)$ & $<0.001$ & & \\
\hline \multicolumn{6}{|l|}{$1-y r$} \\
\hline Weight (kg) & $112.5(20.8)$ & $107.4(21.3)$ & 0.127 & & \\
\hline $\mathrm{BMI}\left(\mathrm{kg} / \mathrm{m}^{2}\right)$ & $39.5(5.4)$ & $36.4(5.8)$ & $<0.001$ & & \\
\hline Waist circumference $(\mathrm{cm})$ & $109.3(16.4)$ & $103.4(16.2)$ & 0.022 & & \\
\hline \multicolumn{6}{|l|}{ Changes 1-yr } \\
\hline Weight change (\%) & $-6.4(-8.1,-4.8)$ & $-8.9(-10.8,-7.0)$ & 0.050 & & \\
\hline Weight change (kg) & $-7.7(-9.6,-5.7)$ & $-10.3(-12.5,-8.1)$ & 0.078 & $4.0(0.8,7.2)$ & 0.014 \\
\hline BMI change $\left(\mathrm{kg} / \mathrm{m}^{2}\right)$ & $-2.7(-3.4,-2.0)$ & $-3.5(-4.2,-2.7)$ & 0.118 & $1.3(0.1,2.4)$ & 0.029 \\
\hline
\end{tabular}

Data are presented as mean (SD or Cl 95\%) or numbers (\%). Groups are divided by $\mathrm{VO}_{2 \max }$ median $\left(78.3 \mathrm{~mL} \cdot \mathrm{kg}^{-0.75} \cdot \mathrm{min}^{-1}\right)$. Differences between groups analyzed using independent samples t-test or Fisher's exact test (gender) as appropriate. Adjusted differences between groups in term of changes were analyzed using analysis of covariance (ANCOVA) including age, gender and baseline value of outcome variable as covariates 
Table 4 Anthropometrics, cardiorespiratory fitness and weight changes at the 1-yr follow-up in patients percentage increases 3-mo cardiorespiratory fitness

\begin{tabular}{|c|c|c|c|c|c|}
\hline \multicolumn{6}{|c|}{ Percentage increased cardiorespiratory fitness, $\left(\mathrm{mL} \cdot \mathrm{kg}^{-0.75} \cdot \mathrm{min}^{-1}\right)$} \\
\hline & $\begin{array}{l}\text { Below median } \\
(n=71)\end{array}$ & $\begin{array}{l}\text { Above median } \\
(n=72)\end{array}$ & $P$-value & $\begin{array}{l}\text { Adjusted differences } \\
\text { between groups }\end{array}$ & $\begin{array}{l}P \text { - value adjusted differences } \\
\text { between groups }\end{array}$ \\
\hline \multicolumn{6}{|l|}{ Baseline } \\
\hline Gender (female) & $58(81.7 \%)$ & $54(75.0 \%)$ & 0.418 & & \\
\hline Age (years) & $44.3(8.7)$ & $42.3(8.6)$ & 0.156 & & \\
\hline Weight (kg) & $116.9(18.6)$ & $120.2(19.3)$ & 0.303 & & \\
\hline BMI $\left(\mathrm{kg} / \mathrm{m}^{2}\right)$ & $40.7(4.7)$ & $41.2(4.7)$ & 0.548 & & \\
\hline Waist circumference $(\mathrm{cm})$ & $116.0(12.6)$ & $117.2(13.0)$ & 0.576 & & \\
\hline $\mathrm{VO}_{2 \max }\left(\mathrm{mL} \cdot \mathrm{kg}^{-0.75} \cdot \mathrm{min}^{-1}\right)$ & $81.7(13.2)$ & $79.6(15.6)$ & 0.374 & & \\
\hline $\mathrm{VO}_{2 \max }\left(\mathrm{mL} \cdot \mathrm{kg}^{-1} \cdot \mathrm{min}^{-1}\right)$ & $25.0(4.4)$ & $24.2(4.8)$ & 0.307 & & \\
\hline $\mathrm{VO}_{2 \max }\left(L \cdot \mathrm{min}^{-1}\right)$ & $2.89(0.54)$ & $2.88(0.68)$ & 0.919 & & \\
\hline \multicolumn{6}{|l|}{$3-\mathrm{mo}$} \\
\hline Weight (kg) & $109.6(17.7)$ & $110.8(18.4)$ & 0.715 & & \\
\hline $\mathrm{BMI}\left(\mathrm{kg} / \mathrm{m}^{2}\right)$ & $38.2(4.5)$ & $38.0(4.6)$ & 0.773 & & \\
\hline Waist circumference $(\mathrm{cm})$ & $107.8(12.3)$ & $107.2(13.2)$ & 0.774 & & \\
\hline $\mathrm{VO}_{2 \max }\left(\mathrm{mL} \cdot \mathrm{kg}^{-0.75} \cdot \mathrm{min}^{-1}\right)$ & $85.0(14.6)$ & $97.0(19.1)$ & $<0.001$ & & \\
\hline $\mathrm{VO}_{2 \max }\left(\mathrm{mL} \cdot \mathrm{kg}^{-1} \cdot \mathrm{min}^{-1}\right)$ & $26.4(4.9)$ & $30.0(6.1)$ & $<0.001$ & & \\
\hline $\mathrm{VO}_{2 \max }\left(L \cdot \mathrm{min}^{-1}\right)$ & $2.86(0.57)$ & $3.30(0.76)$ & $<0.001$ & & \\
\hline \multicolumn{6}{|l|}{$1-y r$} \\
\hline Weight (kg) & $109.4(19.2)$ & $108.8(21.3)$ & 0.845 & & \\
\hline $\mathrm{BMI}\left(\mathrm{kg} / \mathrm{m}^{2}\right)$ & $38.1(5.3)$ & $37.2(5.8)$ & 0.348 & & \\
\hline Waist circumference $(\mathrm{cm})$ & $106.8(14.4)$ & $104.9(15.5)$ & 0.446 & & \\
\hline \multicolumn{6}{|l|}{ Changes 1-yr } \\
\hline Weight change (\%) & $-6.4(-8.1,-4.7)$ & $-9.7(-11.7,-7.7)$ & 0.014 & & \\
\hline Weight change (kg) & $-7.5(-9.6,-5.5)$ & $-11.4(-13.8,-9.1)$ & 0.013 & $4.0(0.9,7.1)$ & 0.012 \\
\hline BMl change $\left(\mathrm{kg} / \mathrm{m}^{2}\right)$ & $-2.6(-3.3,-1.9)$ & $-3.9(-4.8,-3.1)$ & 0.013 & $1.4(0.4,2.5)$ & 0.010 \\
\hline
\end{tabular}

Data are presented as mean (SD or $\mathrm{Cl} 95 \%$ ) or numbers (\%). Groups are divided by median percentage increased $\mathrm{VO}_{2 \mathrm{max}}$ median (11.6 percentage) from baseline to 3- month follow-up. Differences between groups analyzed using independent samples t-test or Fisher's exact test (gender) as appropriate. Adjusted differences between groups in term of changes were analyzed using analysis of covariance (ANCOVA) including age, gender and baseline value of outcome variable as covariates

diet restrictions most rigidly. Unfortunately, dietary compliance was not registered. Further, CRF may influence the ability to perform non-exercise activity and reduce the number of hours of inactivity, or vice versa, thus increasing weight loss [26-28]. On the other hand, higher body weight could also have limited the non-exercise activity and exercise activity and thus limited the potential to increase CRF. However, the present study did not assess non-exercise activity or exercise activity.

This observational cohort study may also have other limitations. First, only treatment-seeking patients with severe obesity were included, thus limiting the generalizability of the results to similar populations. Second, the study population consisted of predominantly white patients, therefore limiting the generalizations to other ethnic groupings. Thirdly, initial baseline values, age and gender differed slightly between groups below or above median. However, these differences were minimized by adjustments for initial baseline values, age and gender. Fourth, it is possible that patients who were more successful in increasing CRF and/or decreasing body weight were more likely to attend follow-up sessions. This may have led to an overestimation of the possible effect of improved CRF. Finally, patients detailed calorie intake and compliance with the prescribed calorie restriction in the ILI program were not assessed.

If verified, our results may be generalized to similar ILI programs in public health care systems. The possible effect of CRF on weight loss and energy expenditure should, however, be examined further. If increasing CRF causes weight loss in randomized clinical trials, exercising to improve CRF should be 


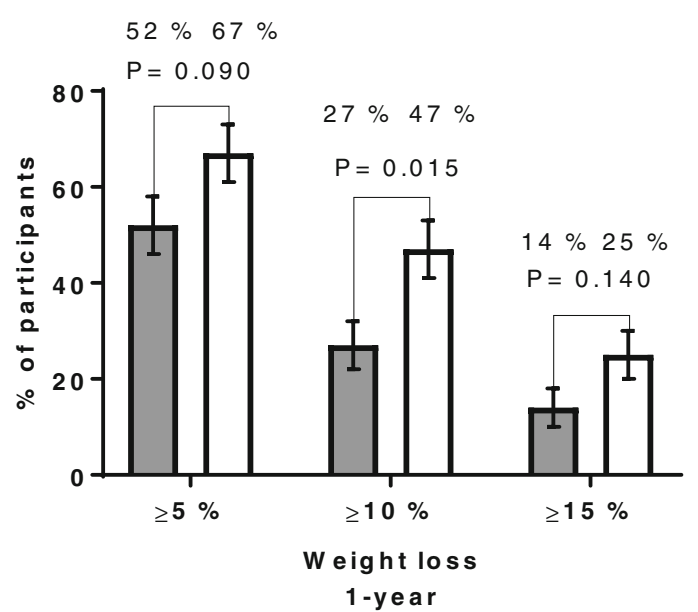

Fig. 4 Proportions of patients in the two groups, who achieved median 3-month percentage increases in CRF, who at 1-year follow-up achieved at least 5, 10\% or 15\% weight loss. Data are presented as percentage of participants with standard error of the mean (SEM), either above or below median 3month percentage increases in CRF, who achieved at least $5,10 \%$ or $15 \%$ weight loss at 1-year follow-up. 3-month percentage increases in CRF above median, $N=72$. 3-month percentage increases in CRF below median, $N=71$. In the above median CRF group, the number of patients who achieved at least $5,10 \%$ or $15 \%$ was $48(67 \%$, SEM 6\%), 34 (47\%, SEM 6\%), $18(25,5 \%)$, respectively. In the below median CRF group, the number of patients who achieved at least $5,10 \%$ or $15 \%$ was 37 (52\%, SEM 6\%), 19 (27\%, SEM 5\%), 10 (14\%, SEM 4\%), respectively

considered as a natural part of future ILI programs in patients with severe obesity. Importantly, increasing CRF has substantial cardiovascular health benefits, regardless of its effect on weight loss [29].

\section{Conclusion}

Among patients with severe obesity who underwent a 1-year ILI program, higher baseline CRF was associated with significantly larger weight loss after 3 months and 1 year. In addition, those with higher initial 3-month CRF changes had greater weight loss at 1 year.

\section{Additional files}

Additional file 1: Intervention. (PDF $99 \mathrm{~kb}$ )

Additional file 2: Supporting information. (PDF $43 \mathrm{~kb}$ )

\section{Abbreviations}

BMI: Body mass index; CRF: Cardiorespiratory fitness; ILI: Intensive lifestyle intervention; $\mathrm{VO}_{2 \text { maz: }}$ : Maximal oxygen consumption

\section{Acknowledgements}

We thank all the patients who took part in this study. Further, we thank the following employees at Vestfold Hospital Trust; Linda Mathisen, Andreas Horsdal, Marita Hole Andersen, Mari Sagaas, Marit Løset Eriksen, Simen Haugen and Ellen Kultorp for sampling and logistics assistance. Thanks are also due to Matthew McGee for proofreading the manuscript.

\section{Authors' contributions}

$J B$ analyzed, interpreted and collected the patient data and was a major contributor in writing the manuscript. ØS analyzed, interpreted the patient data and was a major contributor in writing the manuscript. JKH interpreted the patient data and contributed in writing the manuscript. EG collected the patient data and contributed in writing the manuscript. MCS analyzed and interpreted the patient data and contributed in writing the manuscript. JH analyzed, interpreted the patient data and was a major contributor in writing the manuscript. All authors read and approved the final manuscript.

\section{Authors' information}

$J B$, PhD-fellow and physiologist. ØS (PhD), associated professor and physiologist. JKH (PhD), geneticist. EG (PhD) associated professor and sport educator. MCS (PhD), associated professor and statistician. JH (PhD), MD and professor.

\section{Funding}

No funding was received.

\section{Availability of data and materials}

The datasets used and/or analysed during the current study are available from the corresponding author on reasonable request.

\section{Ethics approval}

Regional Committees for Medical and Health Research Ethics (REC) south east September 22, 2016 (2016/1414).

\section{Consent for publication}

These patients were informed through an opt-out consent letter which stated that previously collected information during the ILI program would be used to answer the research questions stated in this project. Patients had a minimum of three weeks to opt-out of the study, and only two patients reserved usage of their personal information in this study. This opt-out consent procedure was approved by REC south east.

\section{Competing interests}

The authors declare that they have no competing interests.

\section{Author details}

'Morbid Obesity Centre, Vestfold Hospital Trust, Box 2168, 3103 Tønsberg, Norway. ${ }^{2}$ Clinic Medicine and Rehabilitation, Vestfold Hospital Trust, Tønsberg, Norway. ${ }^{3}$ Nature, health and environment, University of Southeast, Bø in Telemark, Norway. ${ }^{4}$ Norwegian Police University College, Stavern, Norway. ${ }^{5}$ Department of Endocrinology, Morbid Obesity and Preventive Medicine, Institute of Clinical Medicine, University of Oslo, Oslo, Norway. 
Received: 14 March 2019 Accepted: 10 June 2019

Published online: 01 July 2019

\section{References}

1. Arciero PJ, Goran MI, Poehlman ET. Resting metabolic rate is lower in women than in men. Journal of applied physiology (Bethesda, Md : 1985). 1993:75(6):2514-20.

2. Shook RP, Hand GA, Paluch AE, Wang X, Moran R, Hebert JR, et al. Moderate cardiorespiratory fitness is positively associated with resting metabolic rate in young adults. Mayo Clin Proc. 2014;89(6):763-71.

3. Miller WM, Spring TJ, Zalesin KC, Kaeding KR, Nori Janosz KE, McCullough PA, et al. Lower than predicted resting metabolic rate is associated with severely impaired cardiorespiratory fitness in obese individuals. Obesity (Silver Spring, Md). 2012;20(3):505-11.

4. Gallagher MJ, Franklin BA, Ehrman JK, Keteyian SJ, Brawner CA, deJong AT, et al. Comparative impact of morbid obesity vs heart failure on cardiorespiratory fitness. Chest. 2005;127(6):2197-203.

5. Dyrstad SM, Edvardsen E, Hansen BH, Anderssen SA. Waist circumference thresholds and cardiorespiratory fitness. J Sport Health Sci. 2019;8(1):17-22

6. Lee CD, Blair SN, Jackson AS. Cardiorespiratory fitness, body composition, and all-cause and cardiovascular disease mortality in men. Am J Clin Nutr. 1999:69(3):373-80

7. Amati F, Dube JJ, Shay C, Goodpaster BH. Separate and combined effects of exercise training and weight loss on exercise efficiency and substrate oxidation. J Appl Physiol. 2008;105(3):825-31.

8. Blair SN, Cheng Y, Holder JS. Is physical activity or physical fitness more important in defining health benefits? Med Sci Sports Exerc. 2001;33(6 Suppl):S379-99; discussion S419-20.

9. Zuntz, in McArdle WD, Katch FI, Katch VL. Exercise physiology : energy, nutrition, and human performance 1991. 1901.

10. de Souza SA, Faintuch J, Sant'anna AF. Effect of weight loss on aerobic capacity in patients with severe obesity before and after bariatric surgery. Obes Surg. 2010;20(7):871-5

11. Nicklas BJ, Wang X, You T, Lyles MF, Demons J, Easter $L$, et al. Effect of exercise intensity on abdominal fat loss during calorie restriction in overweight and obese postmenopausal women: a randomized, controlled trial. Am J Clin Nutr. 2009:89(4):1043-52.

12. Kantartzis K, Thamer C, Peter A, Machann J, Schick F, Schraml C, et al. High cardiorespiratory fitness is an independent predictor of the reduction in liver fat during a lifestyle intervention in non-alcoholic fatty liver disease. Gut. 2009:58(9):1281-8

13. Rosenkilde M, Nordby P, Stallknecht B. Maintenance of improvements in fitness and fatness 1 year after a 3-month lifestyle intervention in overweight men. Eur J Clin Nutr. 2016;70(10):1212-4.

14. Whyte LJ, Gill JM, Cathcart AJ. Effect of 2 weeks of sprint interval training on health-related outcomes in sedentary overweight/obese men. Metabolism. 2010;59(10):1421-8.

15. Miller CT, Fraser SF, Levinger I, Straznicky NE, Dixon JB, Reynolds J, et al. The effects of exercise training in addition to energy restriction on functional capacities and body composition in obese adults during weight loss: a systematic review. PLoS One. 2013;8(11):e81692.

16. DiPietro L, Kohl HW 3rd, Barlow CE, Blair SN. Improvements in cardiorespiratory fitness attenuate age-related weight gain in healthy men and women: the aerobics center longitudinal study. Int J Obes Relat Metab Disord. 1998;22(1):55-62.

17. Ravussin E, Lillioja S, Knowler WC, Christin L, Freymond D, Abbott WG, et al. Reduced rate of energy expenditure as a risk factor for body-weight gain. $\mathrm{N}$ Engl J Med. 1988;318(8):467-72.

18. Gjevestad E, Karlsen TI, Røislien J, Mæhlum S, Hjelmesæth J. The effectiveness of secondary and tertiary care lifestyle intervention in morbidly obese patients: a 1-year non-randomized controlled pragmatic clinical trial. Clin Obesity. 2013;3(1-2):39-50.

19. Ainsworth BE, Haskell WL, Herrmann SD, Meckes N, Bassett DR Jr, TudorLocke C, et al. 2011 compendium of physical activities: a second update of codes and MET values. Med Sci Sports Exerc. 2011;43(8):1575-81.

20. Kent M. The Oxford dictionary of sports science \& medicine. 3rd ed. Oxford New York: Oxford University Press; 2006. vii, 612 p. p

21. Bergh U, Sjodin B, Forsberg A, Svedenhag J. The relationship between body mass and oxygen uptake during running in humans. Med Sci Sports Exerc. 1991;23(2):205-11.
22. Åstrand P-O, Rodahl K. Textbook of work physiology : physiological bases of excercise. 3rd ed. New York: McGraw-Hill; 1986. XII, 756 s. p

23. Hoff J, Kemi OJ, Helgerud J. Strength and endurance differences between elite and junior elite ice hockey players. The importance of allometric scaling. Int J Sports Med. 2005;26(7):537-41.

24. Turley KR, Stanforth PR, Rankinen T, Bouchard C, Leon AS, Rao DC, et al. Scaling submaximal exercise cardiac output and stroke volume: the HERITAGE family study. Int J Sports Med. 2006;27(12):993-9.

25. McArdle WD, Katch FI, Katch VL. Exercise physiology: nutrition, energy, and human performance (7th ed). Philadelphia: Wolters Kluwer Health/ Lippincott Williams \& Wilkins; 2010.

26. Villareal DT, Chode S, Parimi N, Sinacore DR, Hilton T, Armamento-Villareal R, et al. Weight loss, exercise, or both and physical function in obese older adults. N Engl J Med. 2011;364(13):1218-29.

27. Duvigneaud N, Matton L, Wijndaele K, Deriemaeker P, Lefevre J, Philippaerts $\mathrm{R}$, et al. Relationship of obesity with physical activity, aerobic fitness and muscle strength in Flemish adults. J Sports Med Phys Fitness. 2008;48(2): 201-10.

28. Hulens M, Vansant G, Claessens AL, Lysens R, Muls E. Predictors of 6-minute walk test results in lean, obese and morbidly obese women. Scand J Med Sci Sports. 2003;13(2):98-105

29. Wisloff $U$, Ellingsen $O$, Kemi OJ. High-intensity interval training to maximize cardiac benefits of exercise training? Exerc Sport Sci Rev. 2009;37(3):139-46.

\section{Publisher's Note}

Springer Nature remains neutral with regard to jurisdictional claims in published maps and institutional affiliations.
Ready to submit your research? Choose BMC and benefit from:

- fast, convenient online submission

- thorough peer review by experienced researchers in your field

- rapid publication on acceptance

- support for research data, including large and complex data types

- gold Open Access which fosters wider collaboration and increased citations

- maximum visibility for your research: over $100 \mathrm{M}$ website views per year

At $\mathrm{BMC}$, research is always in progress.

Learn more biomedcentral.com/submissions 